\title{
Toward a humanistic approach in psychiatry Afrim Dangellia
}

\author{
Address: Univ. Tirane. Dep. Psikiatrise, 370 Dibra Str., Tirana, Albania \\ from WPA Thematic Conference. Coercive Treatment in Psychiatry: A Comprehensive Review \\ Dresden, Germany. 6-8 June 2007 \\ Published: 19 December 2007 \\ BMC Psychiatry 2007, 7(Suppl I):S66 doi:10.1 186/I47I-244X-7-SI-S66
}

This abstract is available from: http://www.biomedcentral.com/I47I-244X/7/SI/S66

(c) 2007 Dangellia; licensee BioMed Central Ltd.

"To be human, means to be at play" (C.G. Jung). The democratisation of the east european societies caused an important development in the health system of these countries and in particular of mental health. Within the medicine itself, psychiatry as a special branch of it, is undergoing changes rapidly due to this important development in medicine. Relations of psychiatry with the rest of medicine and the relations of psychiatry with the society are changing. In this respect psychiatry deserves special attention. The psychiatry in our times is to overcome some of the challenges that are useful to patients and also to the society. One key challenge is the preservation of the human rights of mentally ill patients. The emphasis on human rights led gradually to the emphasis on the partnership between doctors and their patients and in the treament process. Mental health care is the mirror of the society. All people like freedom and do not want to live in a restricted manner. The trend of today in psychiatry is against large hospitals for mentally ill people, where close spaces and isolation are evident. The process of transition has introduced important events in our everyday life and behavior of people. The creation of new legislation caused the regulation of patients rights, of informed consent, of involuntary hospitalization and also of the treatment. 